\title{
Comfort Properties of Woven Fabrics Produced From Twist-Less Weft Using PVA Yarns

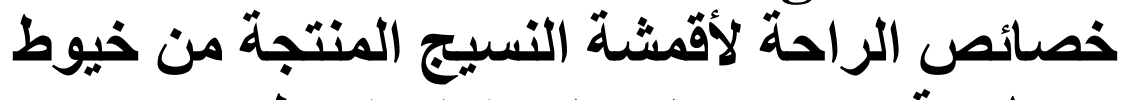

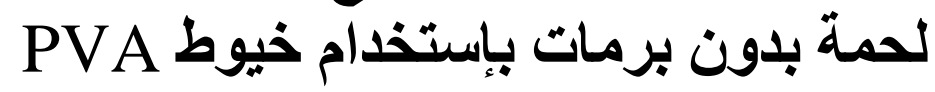

\section{AlaaArafaBadr\&Ashraf El Nahrawy \\ Textile Engineer Dept., Faculty of Engineering, Alexandria University Alaa300_2000@hotmail.com}

\begin{abstract}
الخلاصة الخة
خاصية الر احة لأقشة النسيج التى تحنوى على خيوط لحمة بدون برمات من خامات قطن وتنسيل تم دراستها في هذا البحث.

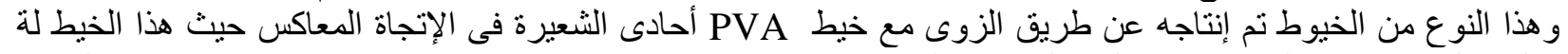

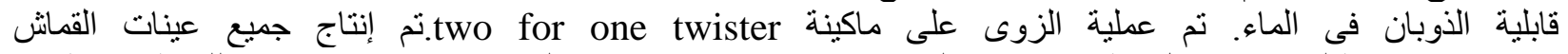

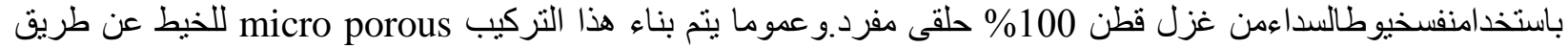

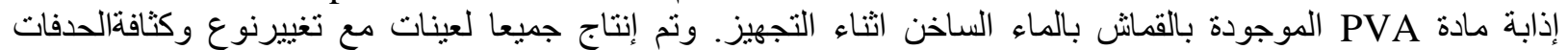

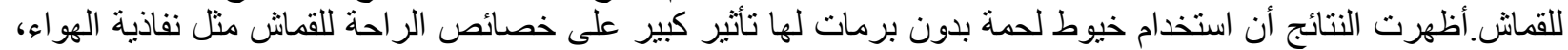

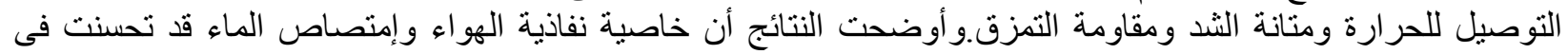

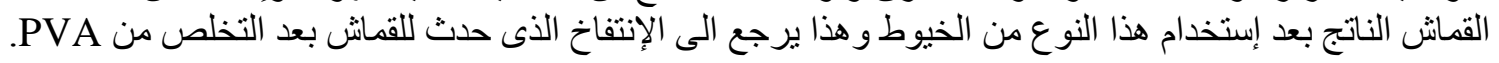

\begin{abstract}
Comfort characteristics of microporous plain-woven fabrics, containing cotton staple fiber twistless and Tencel staple fiber twistless yarn in weft, have been reported in the present paper. The twistless yarn was produced without twist by means of plying with water soluble monofilament PVA filament in the opposite direction. This process was done by TFO (Two for one twister) machine. In all these fabrics the same warp yarn, i.e. a single ring spun $100 \%$ cotton yarn was used. The microporous structure of the yarn is created by dissolving the PVA fibers using hot washing of the fabrics. All sample types of twistless yarns and reference yarns are made with a variation in fiber material and fabric picks $/ \mathrm{cm}$.

The structure of fibrous assemblies in weft has great impact on the comfort related properties, like fabric air permeability, thermal conductivity and also tensile strength and tear resistance. Results indicated that the wickability, and air permeability of the woven fabrics constructed from twistless weft yarn were improved due to the bulkiness of the fabric after dissolving PVA.
\end{abstract}

\section{Key words}

Twistless yarn, microporous fabric, fibrous assemblies, Tencel, PVA, thermal properties, wicking, gain\% and air permeability.

\section{1- Introduction:}

The most essential property of any clothing is comfort. Comfort is an experience that is caused by combination of impulses passed up the nerves from a diversity of external receptors smell, smoothness and color etc in the brain. Comfort is a qualitative expression and it is one of the main features of apparel.
Many consumer research groups have stated that current consumers take into consideration comfort as one of the most significant aspects in their purchase of apparel products. The clothing comfort is dependent onto the mechanical stress, thermal and moisture transfer properties of the fabrics [1].Based on fundamental information on heat and moisture properties, continual efforts are done by 
many scientists to develop the comfort over engineering fibre and fibre assemblies. In one of the various efforts towards improving comfort, the fabrics are produced using a hollow yarn. Recently hollow/micro-porous yarn spinning system and fabric quality therefrom have attracted attention to many textile yarn and fabric manufacturers [2] and research workers [3-6]. The existence of air space inside the yarn affects the transmission features of fabrics. It is essential to reminder that for making the hollow yarn fabrics; bi-component pre-hollow yarn is used to make the fabric; afterwards one component (e.g. polyvinyl alcohol) is dissolved from the pre-hollow yarn at the fabric stage $[7,8]$. The Polyvinyl alcohol is a water-soluble high-molecular compound and is soluble in water at about $60^{\circ} \mathrm{C}$ [7]. Furthermore, Mukhopadhyayet al. [8], said that the pre-hollow yarn fabrics were boiled (hot washed) in water for 25 minutes to remove the PVA.

Additionally, elastic recovery of hollow yarn after taking away the lateral compressive force was higher than elastic recovery of typical friction yarn with the same count [9]. Hollow yarn production targets at reducing fiber packing density. The hollow yarn indicates better compressional recovery. The volume of the hollow yarn after compression is also more than that of the traditional cotton yarn. According to the study of cottonPVA (polyvinyl alcohol) - blended ring spun yarn, Ishtiaque et al. (2008) [10] discovered that the yarn-specific volume of a hollow yarn increases with increase in the PVA percentage. Consequently, the yarn packing factor decreases with the increase in the PVA content, improving yarn thermal comfort, cover factor, smoothness, bulkiness and efficiency in weaving $[11,9]$. Fabrics built of core spun yarn have superior handling, appropriate dimensional properties and pilling resistance. Nevertheless this kind of fabric has disadvantages such as unevenness in dye absorption [12].

Das, Ishtiaque, \& Singh, 2009 [13] also exhibited that plain woven fabrics with micropores have improved thermal resistance and moisture vapour transmission as compared with $100 \%$ cotton fabrics. The removal of watersoluble PVA fibres makes the yarn porous; therefore, fabrics become more compressible. Moreover, there is dearth of literature on the impact of structurally different prehollow/ microporous yarns on yarn tensile and physical properties. Researchers [6] found that the strength of pre-hollow/pre-microporous yarns is better than that of equivalent (normal) cotton yarns which as a result leads to improve spinning and weaving efficiency. Natural and synthetic cellulose fibres give clothing and apparels the highest comfort: softness, strength, good look and functionality [14-15]. Lyocell "Tencel" is a cellulose fibre and has the advantage of being used in a less contaminant spinning process than the one for conventional viscose. It absorbs water perfectly and provides hygienic properties to textile products, has a higher breaking strength, either wet or dry and is commonly used in the apparel industry like underwear. Tencel can also be used in technical textiles and nonwovens. Also, huge differences exist between Lyocell and cotton in both thermal transmission and vapour permeability [16]. Lyocellfibres absorb more moisture than cotton.

Dziworska et al. [17] discovered that fabrics with Lyocell and Tencelfibre wefts were characterized by better air permeability and crease resistance in comparison with fabrics with cotton and viscose wefts.

The comfort characteristics of fabrics primarily depend on the structure and types of yarn used. The development of 
new yarn materials raises questions about the nature and quality of fabrics produced from these new yarns.

The main aims of this research study is to investigate the comfort characteristics of woven fabrics made out of Tencel staple twistless assemblies using two-for-one twister. Our particular objective is to evaluate the ability of these yarn types of distinctive materials to improve the comfort characteristics.

\section{2- Material and Methods}

\section{2-1 Material:}

In this study $100 \%$ Tencel LF, 100\%Egyptian cotton Giza 86 (100\% C)and PVA monofilament(100 Ne) yarns were used to produce twisless woven fabrics. The Polyvinyl alcohol (PVA) is a water-soluble high-molecular compound, white solid, mould ability and excellent electrical insulation. The properties of yarns were given in Table 1. Also, the properties of the Egyptian cotton Giza 86 cotton used in this research work are obvious in the Table 2. For the properties of the Tencel fibers, the fiber length is 38 $\mathrm{mm}$ and the fineness is $1.3 \mathrm{dtex}$.

\section{2-2 Fabric Manufacture:}

All fabric samples were woven on a Sulzerloom machine with 4 heald shafts and with fabric width $300 \mathrm{~cm}$ "WIR".

The fabric picks density was changed at two different levels such as low and high to represent a range of light and mediumwoven fabrics.

All fabric samples were desizing, washing, bleached in the same dyeing bath and then dried usingdrying cylinders and finally all the fabrics were put in the flat form using width setting technique.

\section{2-3 Methodology}

The details of the accomplished design of experiment and sample specifications are shown in Table3.

\section{2-4 Fabric Testing:}

After finishing, all the fabric properties were measured after leaving the samples 72 hours in standard conditions (Relative humidity $=65 \pm 2 \%$ Temperature $=20 \pm 2 c^{\prime}$ ) to give them the chance to relax without any existing stresses.

The fabric count, fabric weight, thickness andair permeability were measured according to ASTM D3775 ASTM D 3776, ASTM D 1777 and ASTM D737respectively. Furthermore, the thermal properties of the samples were measured on the Alambeta testing instrument (in USA) where, in this device the fabric is placed between a hot and a cold plate, the amountof heat flow from the hot plate to the cold plate through the fabric is measured by heat flux sensors. Also the thickness of the fabric is measured $(\mathrm{h})$, which is used to determine the thermal resistance $(\mathrm{r}=\mathrm{h} /$ thermal conductivity) and the thermal absorptivity (b).

The wicking behavior of the sample $(1 * 1$ inch) was measured using a $0.2 \%$ soap solution. The samples were dropped from $1 \mathrm{~cm}$ into the solution "Textile testing by Jewel, Jewel Raul, 2005, page 58, sinking test".

Additionally, gain \% was evaluated according to BS 3449. The percentage gain of the sample " $20 * 20 \mathrm{~cm}$ " were measured by dipping it into water for five minutes, the time taken for complete sinking of the sample was measured in minutes. Then, the sample was hung vertically to allow extra water to drip for another. Finally, Water vapor permeability was measured using ASTM E 96 "Standard Test method for Water Vapor Transmission of materials" - cup method. 
Table 1. Yarn Properties

\begin{tabular}{|c|c|c|}
\hline & $\begin{array}{c}\mathbf{1 0 0 \%} \text { Cotton } \\
\text { Giza 86 }\end{array}$ & $\begin{array}{c}\mathbf{1 0 0 \%} \text { Tencel } \\
\text { LF }\end{array}$ \\
\hline Count (Ne) & 40 & 40.01 \\
\hline Twist (Turns/inch) & 22.8 & 21.89 \\
\hline Uster (CV \%) & 12 & 13.02 \\
\hline Thin places (-50\%) & 1 & 0 \\
\hline $\begin{array}{c}\text { Thick places } \\
(+50 \%)\end{array}$ & 31 & 15 \\
\hline Neps + 200 & 60 & 42 \\
\hline RKM (CN/tex) & 18 & 21.93 \\
\hline Elongation \% & 4.6 & 7.37 \\
\hline Hairiness (H) & 5.9 & 5.35 \\
\hline
\end{tabular}

Table 2. Fiber Properties

\begin{tabular}{|c|c|c|c|c|c|c|c|c|c|}
\hline & Len & Unif. \% & Str. & Elong. \% & MIC & Mat.\% & Rd & +b & Neps/gm \\
\hline $\begin{array}{c}\text { Egyptian } \\
\text { cotton } \\
\text { Giza 86 }\end{array}$ & 32.6 & 88.1 & 45.8 & 5.9 & 4.25 & 89 & 79.0 & 8.4 & 65 \\
\hline
\end{tabular}

Table 3. Design of experiments and samples specifications

\begin{tabular}{|c|c|c|c|c|c|}
\hline $\begin{array}{c}\text { Sample } \\
\text { Number }\end{array}$ & Yarn Material & $\begin{array}{c}\text { Single or } \\
\text { Ply with } \\
\text { PVA }\end{array}$ & e/cm & p/cm & g/m2 \\
\hline 4 & $\begin{array}{c}100 \% \text { Tencel } \\
\text { LF }\end{array}$ & Single & 42 & 20 & 95 \\
\hline 5 & $100 \%$ Cotton & Single & 42 & 20 & 96 \\
\hline 6 & $\begin{array}{c}100 \% \text { Tencel } \\
\text { LF }\end{array}$ & Ply & 42 & 20 & 99 \\
\hline 7 & $100 \%$ Cotton & Ply & 42 & 20 & 95 \\
\hline 8 & $100 \%$ Cotton & Ply & 42 & 27 & 111 \\
\hline 9 & $100 \%$ Cotton & Single & 42 & 28 & 112 \\
\hline 10 & $\begin{array}{c}100 \% \text { Tencel } \\
\text { LF }\end{array}$ & Single & 42 & 28 & 115 \\
\hline 11 & $\begin{array}{c}100 \% \text { Tencel } \\
\text { LF }\end{array}$ & Ply & 42 & 28 & 120 \\
\hline
\end{tabular}




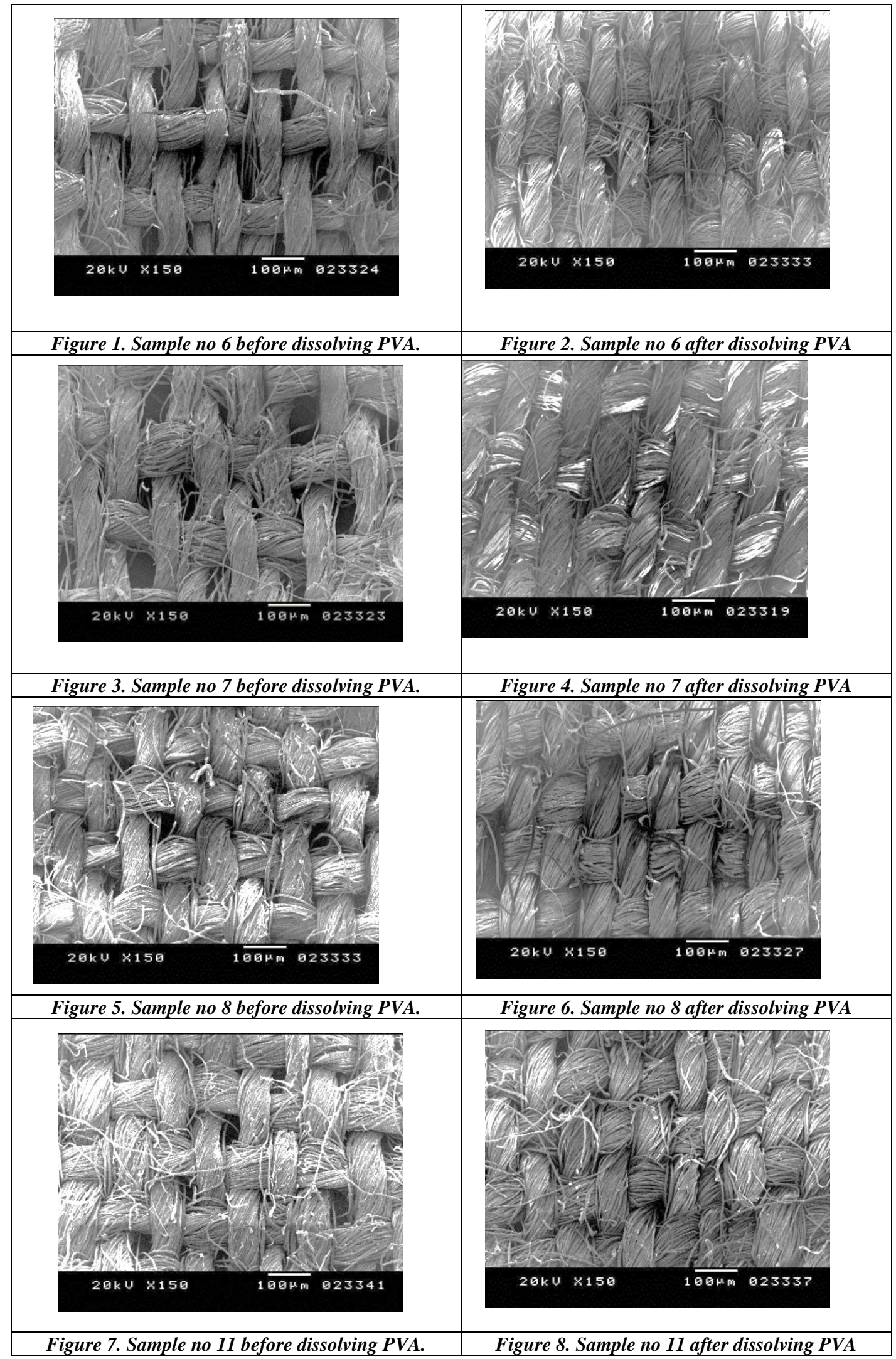

Figures(1-8) Microscopic inspection SEM analysis was forall twisless Samples before and after dissolving PVA 


\section{4- Results and Discussion:}

Table 4illustrates the results of the thermal, wetting and mechanical properties of the woven samples. These results show the performance of the woven fabrics with changing yarn type "single or ply with PVA yarn - twistless technique", yarn material and fabric picks density.

SEM (Scanning Electronic Microscope) analysis was conducted for all twisless samples before and after dissolving PVA.
This microscopic inspection was accomplished in order to examine the surface characteristics of the fabrics. SEM microscopic studies seen in figures 1 to 8 showed that the best appearance and bulkiness are cleared after removal PVA material. It was also observed that woven samples contained twistlessTencel weft yarns seemed to be more brilliant, bulky and uniform than other samples contained Egyptian cotton weft yarn samples

Table 4. Results of Fabric Properties

\begin{tabular}{|c|c|c|c|c|c|c|c|c|c|c|}
\hline $\begin{array}{l}\text { Sample } \\
\text { Number }\end{array}$ & Yarn Material & $\begin{array}{c}\text { Single } \\
\text { or Ply } \\
\text { with } \\
\text { PVA }\end{array}$ & $\begin{array}{c}\text { Air } \\
\text { Permeability } \\
(\mathrm{cm} 3 / \mathrm{cm} 2 / \mathrm{s})\end{array}$ & $\begin{array}{c}\text { Thermal } \\
\text { Conductivity } \\
\text { "W.m.'-1.k }\end{array}$ & $\begin{array}{c}\text { Thermal } \\
\text { Absorptivity } \\
\left(\mathbf{W ~} \mathbf{S}^{1 / 2} / \mathbf{m}^{2} \mathbf{k}\right)\end{array}$ & $\begin{array}{l}\text { Immersion } \\
\text { Time } \\
\text { "Second" }\end{array}$ & $\begin{array}{c}\text { Gain } \\
\%\end{array}$ & $\begin{array}{c}\text { Tear } \\
\text { Strength } \\
\text { "Kge" }\end{array}$ & $\begin{array}{c}\text { Max. } \\
\text { Tensile } \\
\text { Load } \\
\text { "Kge" }\end{array}$ & $\begin{array}{c}\text { Elongation } \\
\%\end{array}$ \\
\hline 4 & $100 \%$ Tencel LF & Single & 83 & 40.4 & 163 & 35 & 149 & 1 & 9.99 & 20.3 \\
\hline 5 & $100 \%$ Cotton & Single & 154.6 & 35.7 & 99.5 & 44 & 140.8 & 0.8 & 8.5 & 19.35 \\
\hline 6 & $100 \%$ Tencel LF & Ply & 133 & 39.9 & 146 & 24 & 155.1 & 1 & 8.96 & 24.94 \\
\hline 7 & $100 \%$ Cotton & Ply & 136.2 & 35.2 & 93.5 & 36 & 143.8 & 0.9 & 8 & 22.37 \\
\hline 8 & $100 \%$ Cotton & Ply & 87.25 & 38.8 & 97.9 & 5 & 118.8 & 0.9 & 13.9 & 26.98 \\
\hline 9 & $100 \%$ Cotton & Single & 46.64 & 40.7 & 130 & 14 & 109.1 & 0.7 & 17.01 & 24.5 \\
\hline 10 & $100 \%$ Tencel LF & Single & 45.98 & 42.6 & 174 & 10 & 115.1 & 0.9 & 19.01 & 25.23 \\
\hline 11 & $100 \%$ Tencel LF & Ply & 54.44 & 41.3 & 154 & 4 & 127.8 & 1.1 & 16.12 & 30.92 \\
\hline
\end{tabular}

\begin{tabular}{|c|c|c|c|c|c|}
\hline $\begin{array}{c}\text { Sample } \\
\text { Number }\end{array}$ & Yarn Material & $\begin{array}{c}\text { Single } \\
\text { or Ply } \\
\text { with } \\
\text { PVA }\end{array}$ & $\begin{array}{c}\text { Thermal } \\
\text { Resistivity } \\
\text { "Tog" }\end{array}$ & $\begin{array}{c}\text { Water } \\
\text { Vapor } \\
\text { Permeability } \\
\left(\mathrm{g} / \mathrm{m}^{2} / \mathrm{hr}\right)\end{array}$ & $\begin{array}{c}\text { Comfort } \\
\text { Index }\end{array}$ \\
\hline 4 & $\begin{array}{c}100 \% \text { Tencel } \\
\text { LF }\end{array}$ & Single & 0.87 & 23.29 & 4.02 \\
\hline 5 & $100 \%$ Cotton & Single & 1.22 & 22.32 & 1.47 \\
\hline 6 & $\begin{array}{c}100 \% \text { Tencel } \\
\text { LF }\end{array}$ & Ply & 0.90 & 32.10 & 3.34 \\
\hline 7 & $100 \%$ Cotton & Ply & 1.31 & 25.39 & 1.77 \\
\hline 8 & $100 \%$ Cotton & Ply & 1.18 & 22.41 & 2.71 \\
\hline 9 & $100 \%$ Cotton & Single & 1.13 & 18.04 & 4.09 \\
\hline 10 & $\begin{array}{c}100 \% \text { Tencel } \\
\text { LF }\end{array}$ & Single & 0.85 & 20.54 & 6.55 \\
\hline 11 & $\begin{array}{c}100 \% \text { Tencel } \\
\text { LF }\end{array}$ & Ply & 0.87 & 26.78 & 7.04 \\
\hline
\end{tabular}

\section{4-1Air Permeability:}

It can be seen that from the following figure that the woven fabric with twistlessweft Tencel ply yarn has more air permeability than other with single Tencelyarn. After removing of
PVA, the yarn will try to achieve a state of minimum energy level i.e. twistless structure. This leads to the bulkiness of twistless yarn while achieving of minimum energy level and this accompanied with the decrease in the 
intensity and packing of fibers in the yarn cross section and increase the availability of more air space in the yarn structure, resulting in increasethe fabric air permeability $(11,18)$. This could be referred to the more open spaces created between the fibers inside yarn cross sectionaftertwistless stage and removing of PVA. Also, it can be seen from figure 9 that thecotton samples behave in a different manner for the increasing of its air permeability than the Tencel fabrics.
These phenomena may be explained bythe ribbon cross section shape of the cotton fibers against the round shape of the Tencel fibers. Thiscotton ribbon shape helps in increasing open spaces insidethe fabric.Moreover, this figure shows the results of changing fabric picks density. It could be noticedthat the fabric with more pick density has lessair permeability than the other samples. The higher picks density makes the yarns to be more adjacent to each-others.

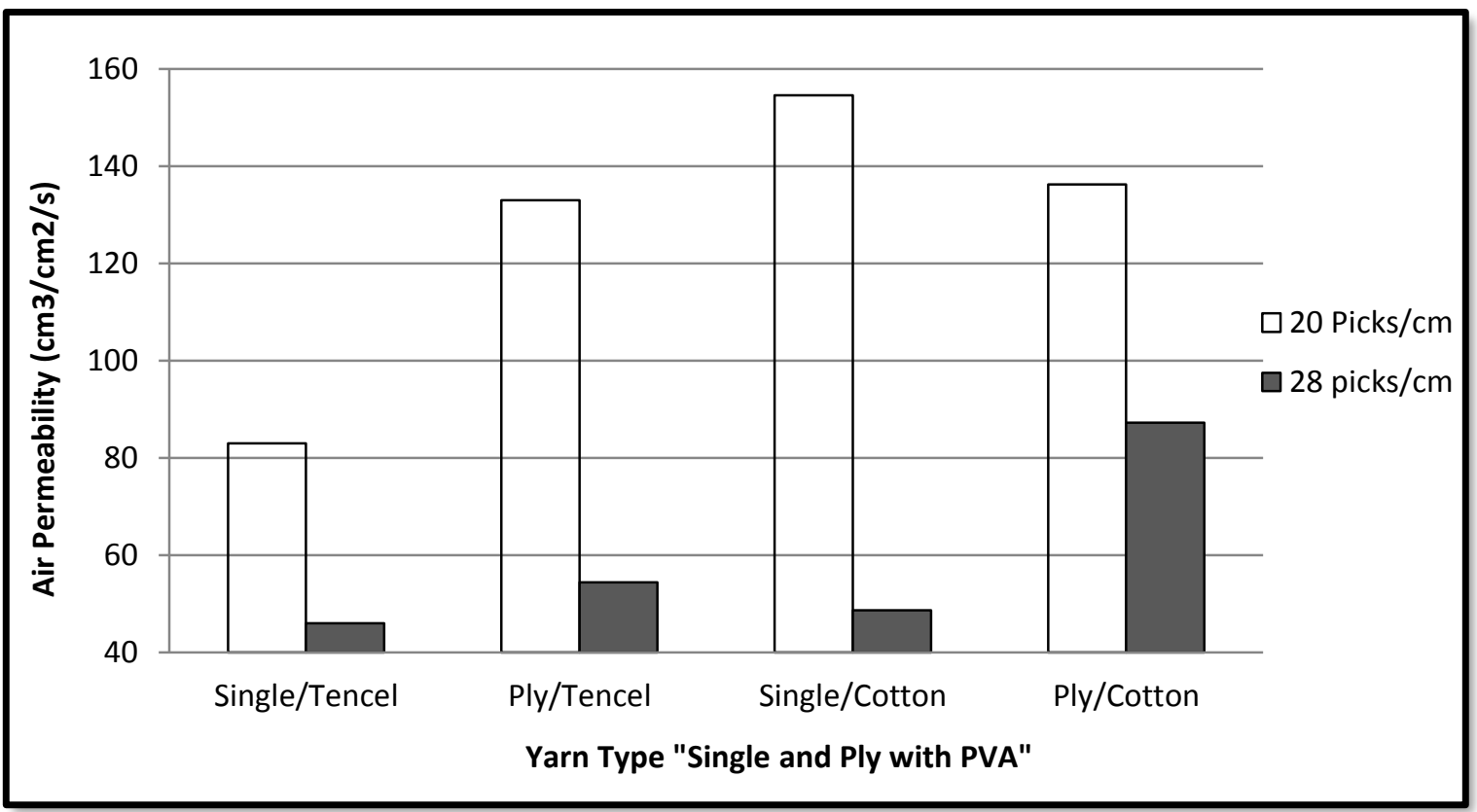

Figure (9) Relation between yarn type and fabric permeability

\section{4-2 Thermal Conductivity:}

As it can be seen from figure (10) that twistlessweft ply yarn has less thermal conductivity than other with single yarn; this is due to the more contained air inside the yarn which represents as a good insulator in spite of the high fabric thickness accompanied with twistless fabric samples.Also Tencel fabric gives higher thermal conductivity which is referred to the high degree of crystallinity and molecular orientation of Tencel fibers Tencel has a unique fibril structure. Fibrils are the tiniest components which form the fiber. The channels between the individual fibrils control absorption and release of moisture. Therefore, these small fibrils guarantee the best transportation of moisture(19).

It is noticed that the higher fabric picks density gives more thermal conductivity than other samples. This difference is related to the more material accompanied with higher fabric density which makes it to be a good conductor of the heat. 


\section{4-3 Thermal Absorptivity:}

Figure (11) shows the relation between yarn type "single or ply with PVA" and the thermal absorptivity for different fabric picks density. It could be seen from figure (11) that the both the twistless effect and the fiber material affect the thermal absorptivity.It is clear from the figure that the twistless fabrics gave less absorptivity thanthe samples woven with single yarn. The thermal absorptivity of yarn depend on its available specific surface, the lower no of fibers in yarn cross section for the twistless weft yarn results in decreasing specific surface which is proportional to the thermal absorptivity due to availability of air spaces which reduces fabric thermal absorptivity. Also the Tencelfibers heighten thermalabsorptivity and this agrees with the previous thermal conductivity trend.This means that the Tencel gives cool feeling when touch.

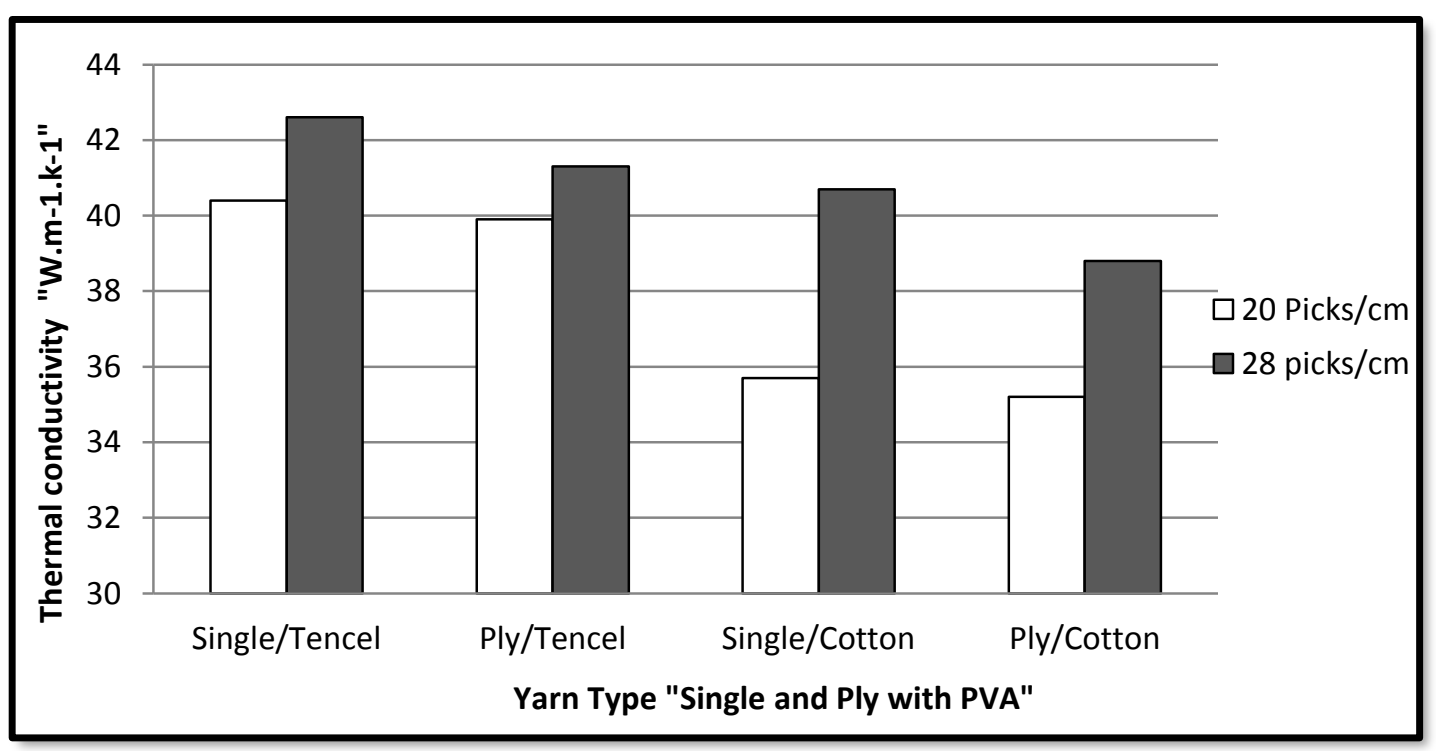

Figure (10) Relation between yarn type and thermal conductivity

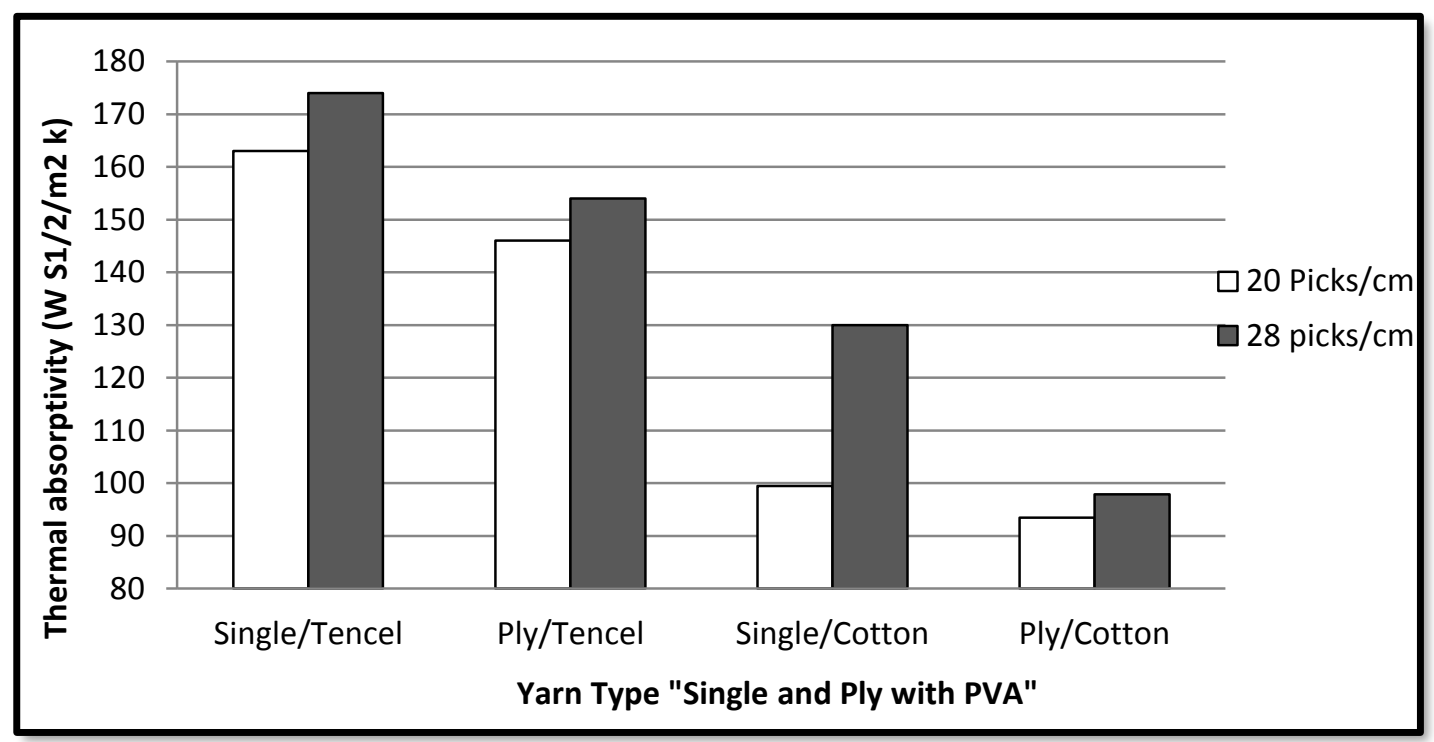

Figure (11) Relation between yarn type and thermal absorptivity 


\section{4-4 Fabric Moisture Properties:}

For the wicking behavior of the sample, the following figure (12) shows the factors affecting the immersion time (sec).It can be seen that the fabric produced from twistless weft yarn gave less immersion time. The impact of removal of PVA on the improving of wicking characteristics of woven fabric is due to the increase of the openness of fabric and yarn bulkiness resulting in availability of more air spaces in yarn structure.Furthermore, parallel arrangement of fibers creates proper channeling within the yarn, leading to increase in wicking $(20,21)$. It is clear from the same figure that the fabric wettability was improved with using Tencel fibers than cotton fibers.Furthermore, figure (13) shows that gains $\%$ for the woven fabric produced withtwistless weft ply yarn has more air permeability than other with single yarn. It is clear from this figure that the gain $\%$ for the fabrics woven from Tencel fibers is more than the other samples. The fabriccan keep more water inside its fabric. Furthermore, Raj (22) defined the Comfort Index for summer clothing as follows:

Comfort Index $(\mathrm{CI})=(\mathrm{MTR} * \mathrm{AR}) / \mathrm{TR}$ Where:

MTR = Water Vapor Permeability $\left(\mathrm{g} / \mathrm{m}^{2} . \mathrm{hr}\right)$

$\mathrm{AR}=$ Air Resistance Value (kpa.s/m)

$\mathrm{TR}=$ Thermal Resistance Value (Tog)

Summer fabrics should possess high permeable characteristics to both air and moisture and also should have low thermal resistance.Consequently, table 4 shows the value of the comfort index for every sample. It can be noticed that sample number 11 which produced from twistless weft Tencel yarn at picks density 28 has the highest thermo-physiological comfort index for summer clothing.

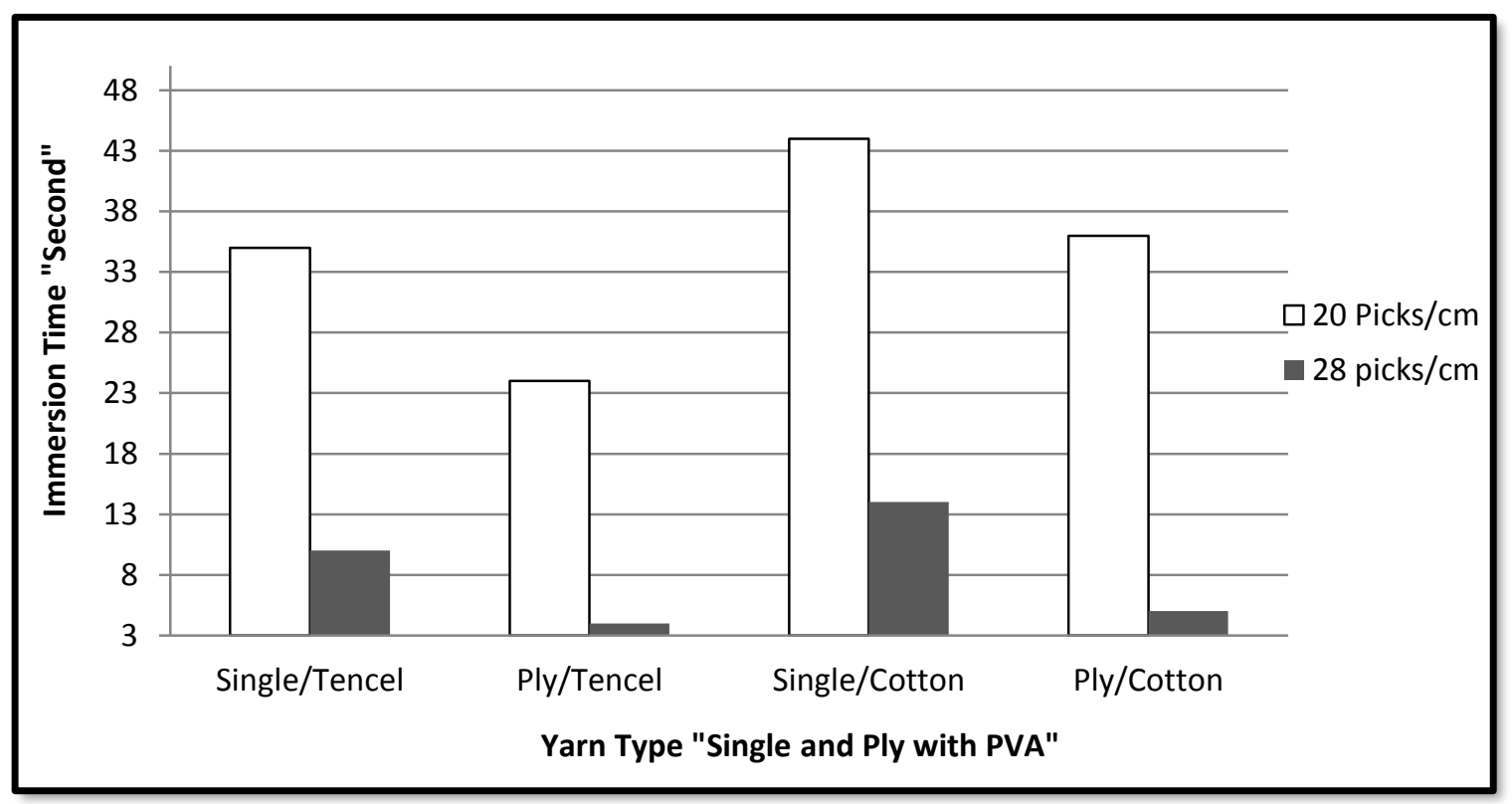

Figure (12) Relation between yarn type and fabric immersion time 


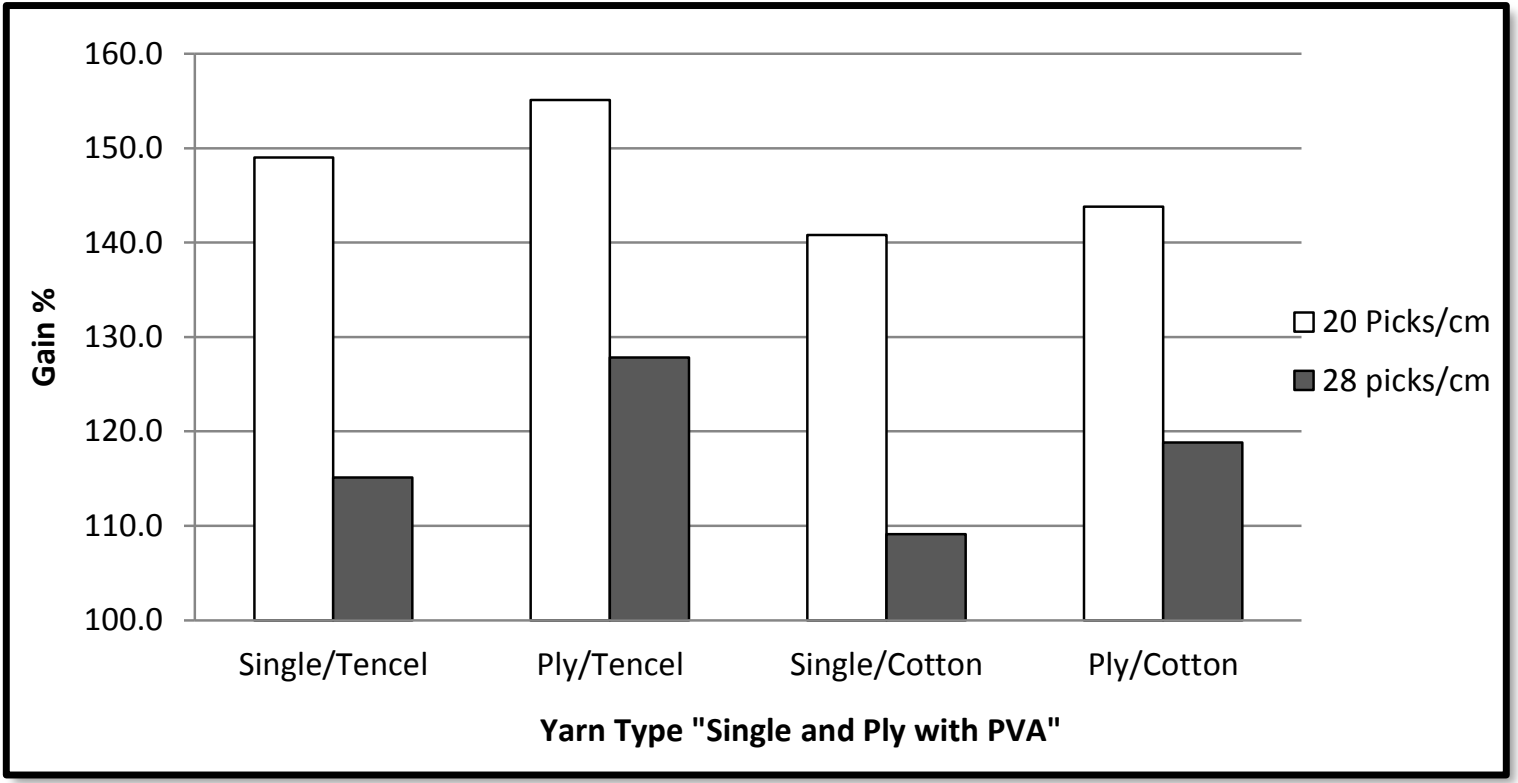

Figure (13) Relation between yarn type and fabric gain \%

\section{4-5Tear Resistance}

Figure (14) shows that the twistless weft yarn, fiber type and fabric picks density affect the woven fabric tear strength. It can be seen that the fabric tear strengthin the weft direction for the ply yarn with PVA is higher than the single yarn. The tear strength is primarily depends on the yarn strength, yarn surface characteristics and fabric structure. From a different point of view, the alignment of fibers in yarn as well plays an essential role. The tightness of the fabric structure controls how many yarns carry the load. A tight fabric permits only one yarn to break at a time as the tear propagates. A loose fabric allows more yarns to carry the load at any one time(23). In this study, we have compared the fabrics of same structure with differentkinds of weft yarns. The higher tear strength of fabric woven with twistless weft yarn is mostly due to two causes: (i) the smooth surface of twistless yarn which permits to slide within delta zone and consequently more than one yarn carry the load at one time, and (ii) the orientation of fibers along the axis of yarn results in maximum sharing of load. Moreover, it is clear that Tencel fabrics improves tear strengthin weft direction. This might be due to the higherstrength and breaking elongation percentage of Tencel yarns against the cotton yarns.

\section{4-6 Fabric Tensile Strength:}

The woven fabric produced from twistless weft yarn has a higher tensile strength in the weft direction than the normal single yarn as cleared in figure (15). Once the twistless yarn has been established inside the fabric structure, the compacting forces created by the fabric structure itself hold the system together. Also, this may be due to the fact that the compacting forces created in fabric structure itself result in higher inter-fiber friction force. In addition, the parallel orientation of fibersin weft yarn along the load direction lead to uniform and maximum load sharing by all the component fibers in weft direction of the fabric. The structural characteristics of Tencel fibers are responsible for their superior mechanical properties. Tencel 
fibers have high degree of crystallinity and orientation, as well as high molecular mass and degree of polymerization as obvious in same figure. This enables Tencel fibers to reach high tensile strength and modulus.

The higher breaking elongation of twistlessyarn in comparison with typical singleyarn could be attributed to the empty space at the twistless yarn central zone and looser structure which gives the chance for lateral contraction.Higher compaction and contraction of twistless yarn under tensile load, is accompanied by higher fiber entangling and hence higher breaking elongation as shown in figure (16).

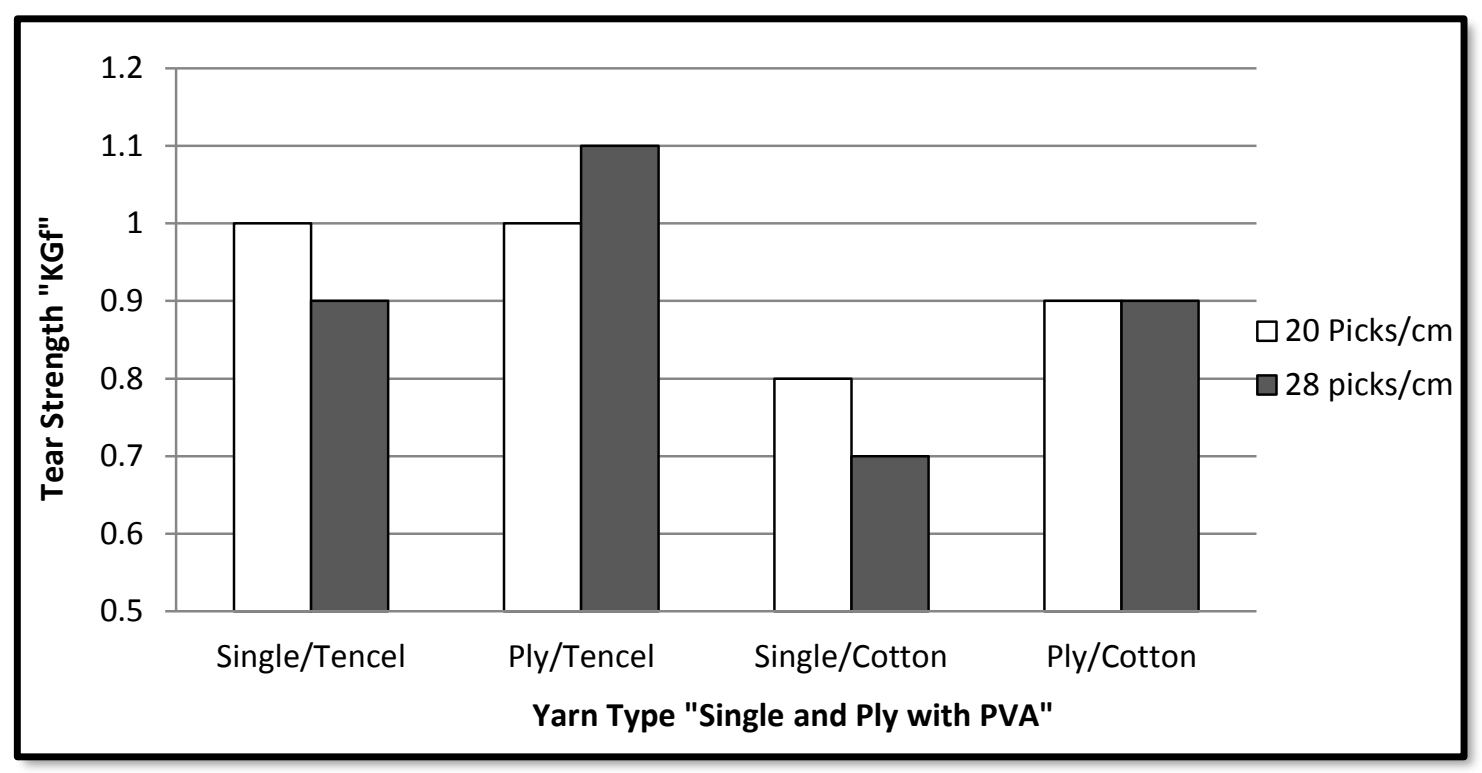

Figure (14) Relation between yarn type and fabric tear strength

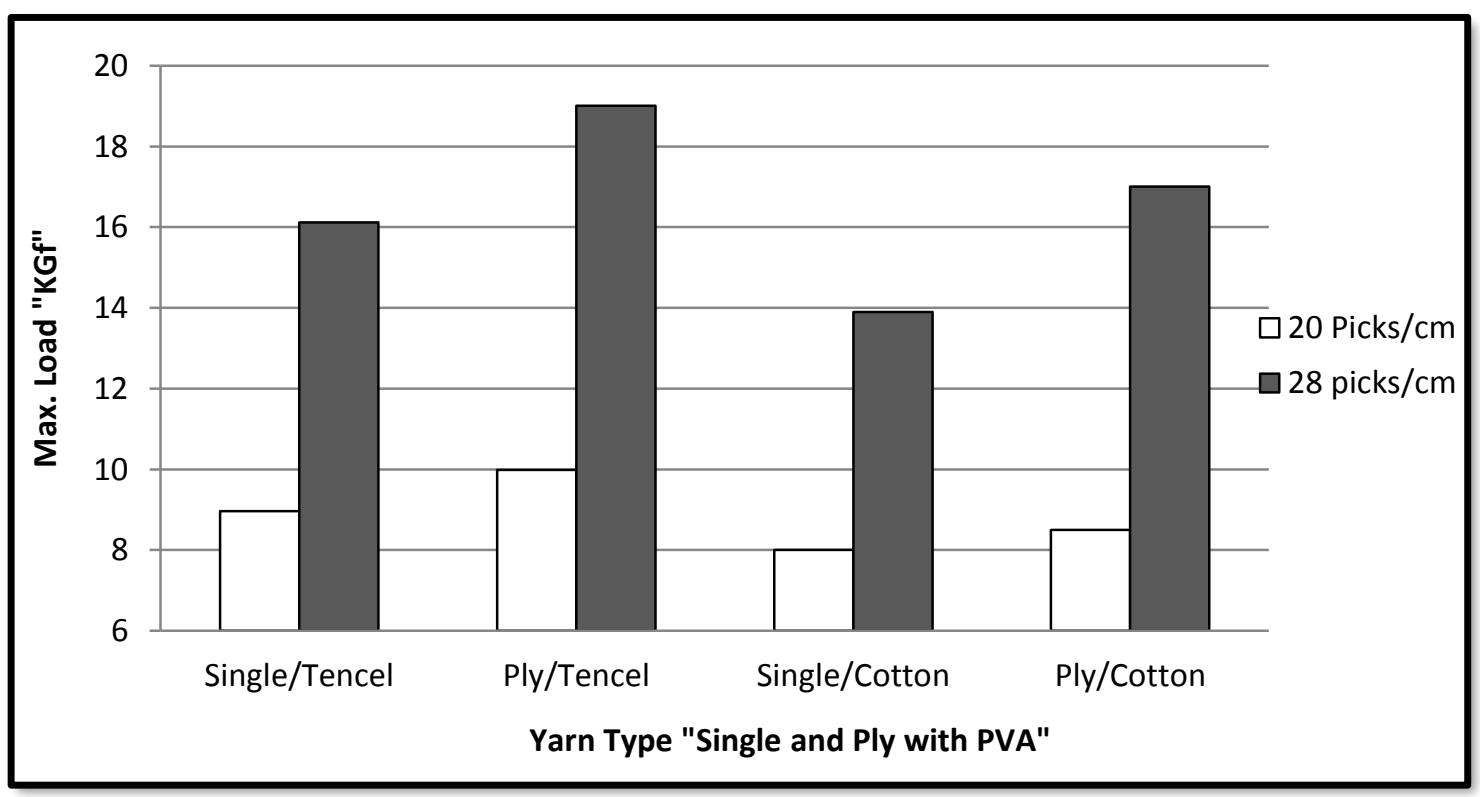

Figure (15) Relation between yarn type and fabric tensile strength 


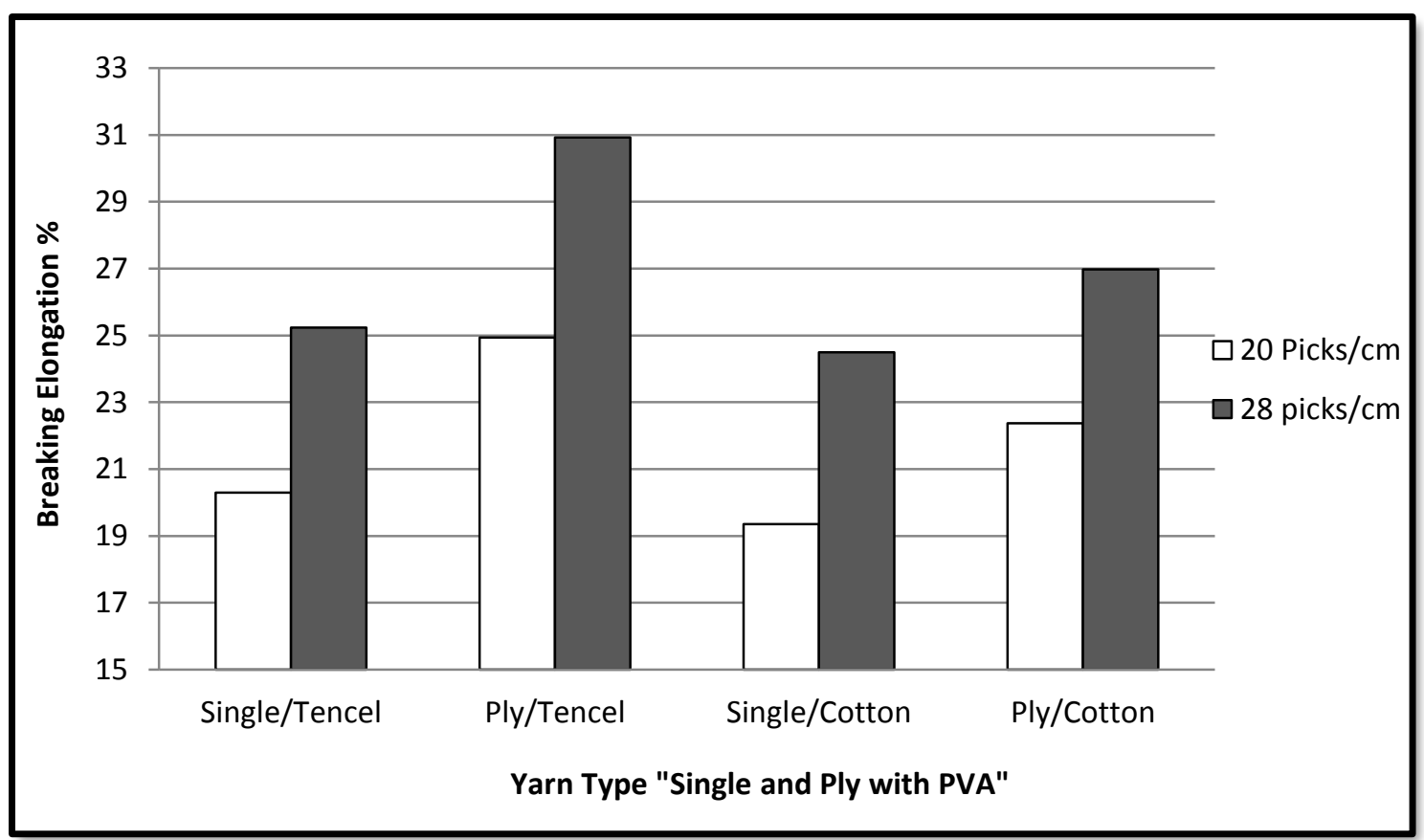

Figure (16) Relation between yarn type and fabric elongation

\section{5-Conclusion:}

In this research, thermal, wetting and mechanical properties of woven fabrics produced from twistlessweft yarn using PVA and different yarn material have been studied.Comfort characteristics of plainwoven fabrics has been improved after using PVA twistless weft yarn. Within this research work, fabric woven with twistless weft ply yarn has more air permeability, wickability, gain \%, tear strength, elongation $\%$ than other with single yarn.Furthermore, fabric thermal conductivityand thermal absorptivity are decreasing for fabrics produced from twistless weft yarn.

Results show that for the fabric have Tencel yarn, the air permeability, thermal conductivity, thermal absorptivity, wickability, gain \%, thermo-physiological comfort index,tear strength, tensile strength and elongation $\%$ are increasedthan other woven fabrics contained cotton weft yarns.
The unique structure andthe smooth surface of twistless weft Tencel yarnresult inenhanced physiological and mechanical functions that make itstand out amongst the family of cellulosic fibers.

\section{Acknowledgement}

We appreciate the co-operation of Polymer and Fiber Engineering Department, Auburn University, USA for permitting us to use their testing facilities.

\section{References}

[1]Li, Y., "The Science of Clothing Comfort", Textile Progress, 31(1/2), 1-135, 2001.

[2] "Pursuing comfort by 'Spinair' " High function textiles; Asian Textile Business, pp. 30-35., December 2001.

[3] Merati, A. A., Okamura, M.; "Hollow yarn in friction spinning; Part II: Yarn structure and deformation under axial tension and lateral forces"; Textile Research Journal, 71(5), pp.454 - 458., 2001. 
[4] Merati, A. A., Okamura, M.; "Limits of hollow yarn in friction spinning"; Textile Research Journal, 73(6), pp.496-502, , 2003.

[5]Das A., Ishtiaque, S. M., Yadav, P.; "Contribution of core and sheath components to the tensile properties of REF-III yarn"; Textile Research Journal, 74(2), pp.134-139, 2004.

[6] Ishtiaque, S. M., Das, A., and Singh, R. P.; "Packing of micro-porous yarn: Part I. Optimization of yarn characteristics"; Journal of the Textile Institute, 99(2), pp.147-155, April 2008.

[7]Das, A., Ishtiaque, S.M.; "Comfort characteristics of fabrics containing twist-less and hollow fibrous assemblies in weft"; Journal Textile and Apparel Tech. Management, , 3(4), pp.1 7, 2004.

[8] Mukhopadhyay, A., Ishtiaque, S. M., Uttam, D.; "Impact of structural variations in hollow yarn on heat and moisture transport properties of fabrics"; Journal of the Textile Institute, 102 (8), pp. 700-712, 2011.

[9] Merati, A.A. and Okamura, M., "Hollow Yarn in Friction Spinning, Part 2: Yarn Structure and Deformation under Axial Tension and Lateral Forces", Text. Res. J., Vol. 71, No. 5, pp. 454-458, 2001

[10] Ishtiaque, S.M., Das, A., \& Singh, R.P., "Packing of micro-porous yarn: Part I. Optimization of yarn characteristics". Journal of the Textile Institute, 99,pp. 147-155, 2008

[11] Merati, A.A. and Okamura, M., "Hollow Yarn in Friction Spinning, Part 1: Tensile Properties of Hollow Yarn", Text. Res. J., Vol. 70, No. 12, pp. 1070-1076, 2000
[12] Sawhney, A.P.S., Ruppernicker, G.F. and Robert, K.Q., "Cotton Covered Nylon-Core Yarn and Greige Fabrics", Text. Res. J., Vol. 59, No. 4,pp.185-190, 1989

[13] Das, A., Ishtiaque, S.M., \& Singh, R.P., "Packing of micro-porous yarns: Part II. Optimization of fabric characteristics. Journal of the Textile Institute, 100,pp. 207-217, 2009

[14] Ibbett R. N., Hsieh Y. L."Effect of fibre swelling on the structure of Lyocell fabrics" Text. Res. J, 71(2), pp. 164-173, 2001.

[15] Valldeperas J., Carrillo F., "Lis M., Navarro J. A.; Kinetics of enzymatic hydrolysis of Lyocellfibres" Text. Res. J, 70(11), pp. 981-984, 2000.

[16] Eichinger D., Bartsch P., Schafheitle P., Kreuzwieser C.; "Wearer comfort properties of LenzingLyocell" ITB Int Text Bull 45(3), pp. 58-60, 1999.

[17] Dziworska G., Frydrych I., MatusiakM.,andFilipowska B.; "Aesthetic and hygienic properties of fabrics made from different cellulose raw materials"Fibres Text East Eur, 8(2), pp. 46-49, 2000.

[18] Lord P R, "Handbook of Yarn Production" $1^{\text {st }}$ edn (Woodhead, Cambridge), 322, 2003.

[19] http://www.lenzing.com/en/fibers/ten cel/moisture-control.html "Moisture absorption of Tencel is more".

[20] Anbahan S \&Prasad P, "Modeling the In-Plane Permeability of Woven Geotextiles1", Text Res J, 69 (5), 345-351, 1999.

[21] Ansari N \&Haghighat Kish M, "The Wicking of Water in Yarn as Measured by an Electrical Resistance Technique", Journal of the Textile Institute, 91(3), 410-419, 2000.

[22] Raj S. and Sreenivasan S., "Total Wear Comfort Index as an Objective 
T: 14 AlaaArafaBadr \& Ashraf El Nahrawy

Parameter for Characterization of Overall Wearability of Cotton Fabrics", Journal of Engineered Fibers and Fabrics, Volume 4, Issue 4, pp. 29-41, 2009.

[23] Lord P R \&Radhakrishnaiah P, "A Comparison of Various Woven Fabrics Containing Friction, Rotor, and Ring Spun Cotton Yarn Fillings", Text Res J, 58 (6), 354362, 1988. 